AGH DRILLING, OIL, GAS • Vol. $31 \cdot$ No. $1 \cdot 2014$

http://dx.doi.org/10.7494/drill.2014.31.1.99

\author{
Joanna Przybylowicz*, Stanisław Rychlicki*
}

\title{
ENHANCED OIL RECOVERY PROCESSES IN SANDSTONE RESERVOIRS CONTAINING LIGHT OIL IN OFFSHORE FIELDS**
}

\section{INTRODUCTION}

The initial stage of oil production is based on mechanisms employing natural reservoir energy. When primary methods are not profitable, secondary methods have to be involved. They are aimed at maintaining pressure in the reservoir and movement of hydrocarbons towards the production wells. If production with the use of secondary methods is no longer economically effective, the Enhanced Oil Recovery (EOR) methods are employed. This approach refers to the tertiary oil recovery methods. The EOR methods support the recovery oriented to energy production which substitutes or helps primary and secondary methods. The applied activities are based on, among others, providing heat, changing oil properties as well as chemical reactions between injected fluids and oil. Among EOR methods we have: thermal methods (steam stimulation, cyclic steam injection, steam or hot water injection, bed combustion), chemical methods (polymer injection, surfactants injection), gas injection (miscible solvents, air, nitrogen, $\mathrm{CO}_{2}$ ) and other (microbiological, mechanical and electrical) [17].

The EOR methods are used for elongating the time of oil extraction from a reservoir at the initial stage of production to reduce the exploitation costs. The use of any of tertiary methods mainly depends on the characteristic of the reservoir, properties of formation fluid and environment. The lithology of the reservoir and specific weight of oil (light, medium, heavy) are particularly important. The EOR methods implementation in the offshore conditions is more complex than onshore. The enhancement methods used for sandstone formations containing light oil are addressed in this paper. The environmental conditions were accounted for when selecting the processes.

* AGH University of Science and Technology, Faculty of Drilling, Oil and Gas, Krakow, Poland

** Work performed within the statutory research program of Faculty of Drilling, Oil and Gas AGH UST 
A list of oil and reservoir properties for selected EOR methods are presented in Table 1. The ranges and average values of parameters characterizing oil and reservoir are indicated. It must be born in mind that the presented values are only of informative character and should not be treated as constant threshold values [2].

\section{APPLICATION OF EOR METHODS IN SANDSTONE FORMATIONS}

The reservoir lithology is one of the basic criteria determining the applicability of particular EOR methods. Thermal and chemical methods are more frequent in sandstone reservoirs than in other lithologies. In the first decade of the $21^{\text {st }}$ century most of EOR field projects were performed in sandstone reservoirs [3].

Thermal methods are especially important for enhancing heavy oil production. The use of these methods is associated with the reduction of oil viscosity, and so, higher depletion coefficient. Among the thermal methods which are most frequently applied for sandstone reservoirs with heavy oil are steam injection and cyclic steam injection. The correct understanding of the bed combustion and its applicability require much attention before using this option at a large scale. In the case of heavy oil there are also used such methods as: Steam Assisted Gravity Drainage (SAGD), LASER method, THAI (Toe-to-Heel Air Injection) method and CAPRI (catalytic version of THAI) method [4].

In the case of light oil fields the shape of steam injection operation is minor. Steam may remove volatile components leaving only the nonvolatile part. If high enthalpy steam is to be used, it should be injected at suitable pressure, which means a limited depth range within which this method can be applied [8]. Recently much attention has been paid to the HighPressure Air Injection (HPAI) method. It must be noted however that all HPAI projects were performed in carbonate reservoirs. In the combustion processes performed in-situ the operation of high-pressure air or oxygen may create considerable safety problems [4].

The chemical properties of injected substances increase the mobility of oil towards production wells. The use of chemical methods is particularly important in the case of reservoirs with high permeability contrast and presence of thief zones, and also when the oil viscosity is higher than water viscosity. Now the most common chemical method applies a mixture of polymers and water [3]. As far as the field applications review is concerned, the polymeric injection may be treated as the most mature technology. Apart from polymers also alkali and surfactants are injected to sandstone environment during EOR processes. For increasing oil production also the Alkaline Surfactant Polymer (ASP) method has been incorporated.

The selection of the most suitable EOR method based on gas injection $\left(\mathrm{CO}_{2}, \mathrm{~N}_{2}\right.$, hydrocarbon gas, flue gas) should be made in view of the formation conditions and structure of fluids inside the reservoir. Production can be enhanced as a consequence of miscible oil displacement process or displacing fluid injection. Miscible displacement is part of the applied EOR method when the light oil fields are involved [4]. It mainly depends on the reservoir pressure. As a consequence of this process the volume of oil increases, and so its viscosity decreases. The weight of oil conditions its displacement ability. Gas reveals much higher liability to penetrate viscous fluids than water. 


\begin{tabular}{|c|c|c|c|c|c|c|c|c|c|c|c|c|c|c|}
\hline \multirow{12}{*}{ 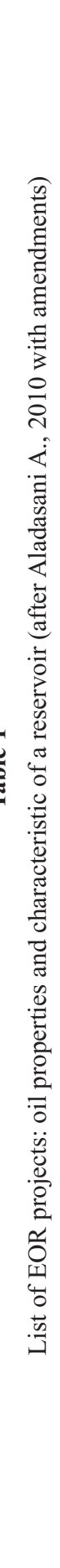 } & \multirow{12}{*}{ 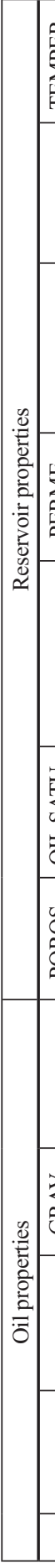 } & 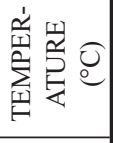 & & 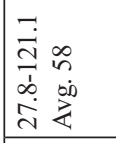 & 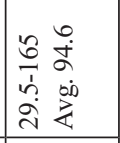 & 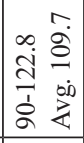 & 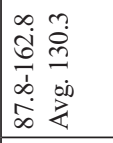 & & 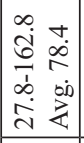 & 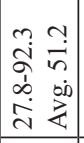 & 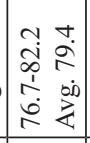 & 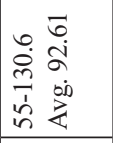 & & 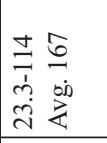 \\
\hline & & 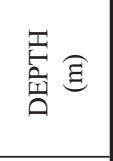 & & 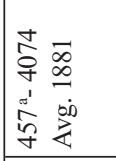 & 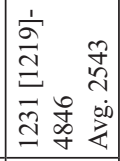 & 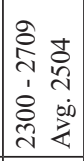 & 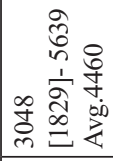 & & 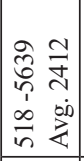 & 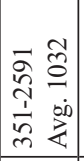 & 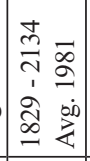 & 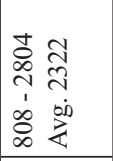 & & 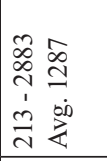 \\
\hline & & 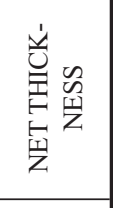 & & 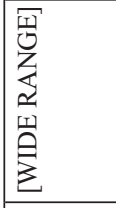 & 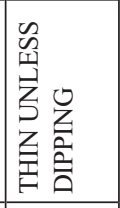 & $z$ & 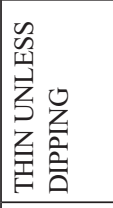 & & & & & & & Z \\
\hline & & 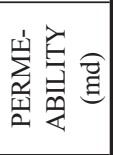 & & 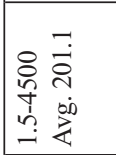 & 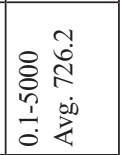 & 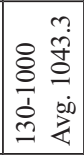 & \begin{tabular}{ll} 
& 0 \\
$n$ & \multicolumn{1}{c}{} \\
$\tilde{n}$ & 0.0 \\
& 2 \\
0 & 2
\end{tabular} & & 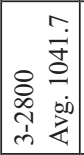 & 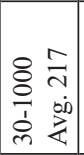 & 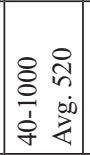 & 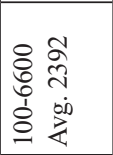 & & $\begin{array}{ll}8 & 7 \\
0 & \dot{5} \\
n & \infty \\
n & \infty \\
1 & 00 \\
\infty & 0 \\
-i & z\end{array}$ \\
\hline & & 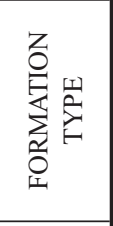 & $\mid$\begin{tabular}{c}
$z$ \\
0 \\
0 \\
0 \\
\cline { 1 - 1 } \\
$z$
\end{tabular} & 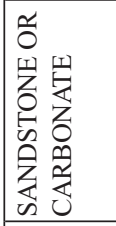 & 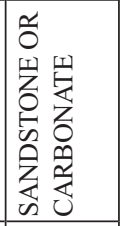 & 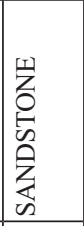 & 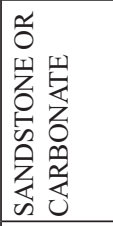 & 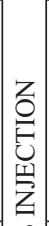 & 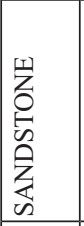 & 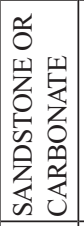 & 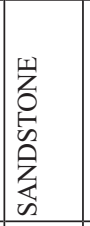 & 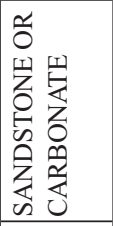 & 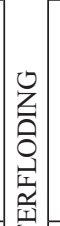 & 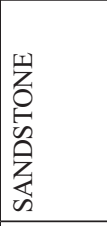 \\
\hline & & 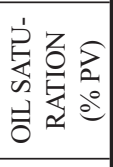 & $\begin{array}{c}0 \\
0 \\
0 \\
\text { 至 } \\
0 \\
0 \\
0 \\
0\end{array}$ & 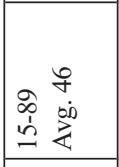 & 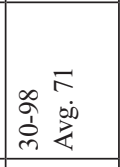 & & 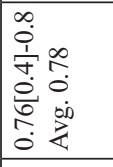 & 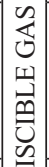 & 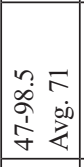 & 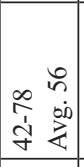 & 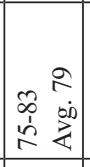 & $\begin{array}{l}\infty \\
\infty \\
\infty \\
\infty \\
\end{array}$ & 空 & 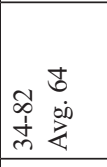 \\
\hline & & 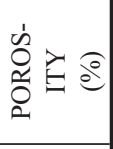 & $\stackrel{\mathscr{n}}{\Sigma}$ & $\begin{array}{ll} & \infty \\
\dot{ \pm} \\
\hat{n} & 0 \infty \\
\dot{n} & z\end{array}$ & 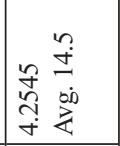 & 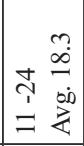 & 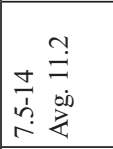 & $\sum_{i=1}$ & 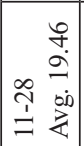 & 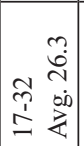 & 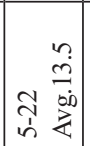 & 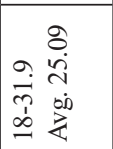 & 至 & 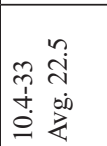 \\
\hline & & 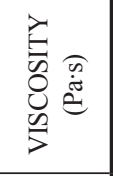 & & 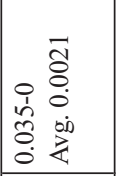 & 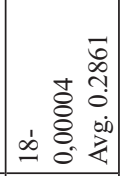 & 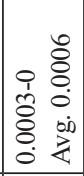 & 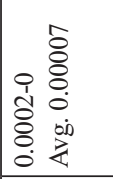 & & 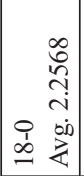 & 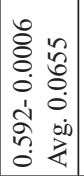 & 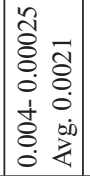 & 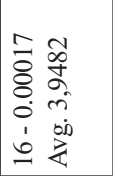 & 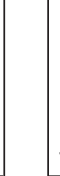 & 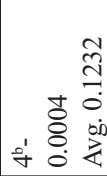 \\
\hline & & 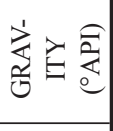 & & 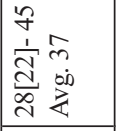 & 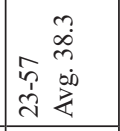 & 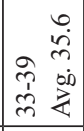 & 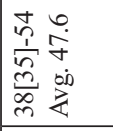 & & 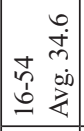 & 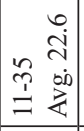 & 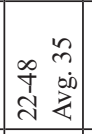 & 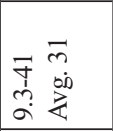 & & 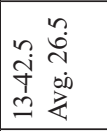 \\
\hline & & 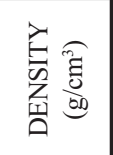 & & 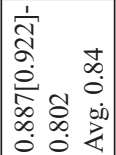 & 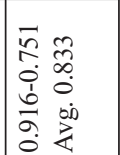 & 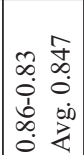 & 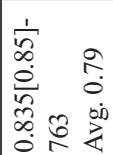 & & 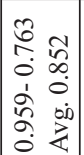 & 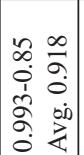 & 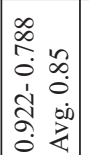 & 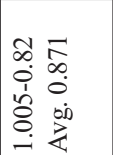 & & $\mid \begin{array}{ll}m & 0 \\
\infty & 0 \\
0 & 0 \\
0 & 0 \\
0 & 0 \\
\hat{\sigma} & 0 \\
0 & 0 \\
0 & 2\end{array}$ \\
\hline & & 哭总 & & $8^{\sim}$ & 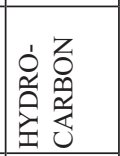 & 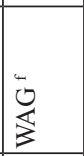 & 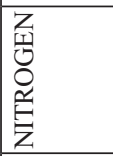 & & 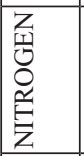 & $8^{2}$ & 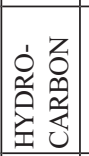 & 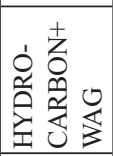 & & 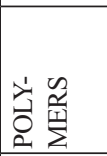 \\
\hline & & $\dot{z}$ & & - & 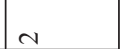 & & & & & & & & & \\
\hline
\end{tabular}




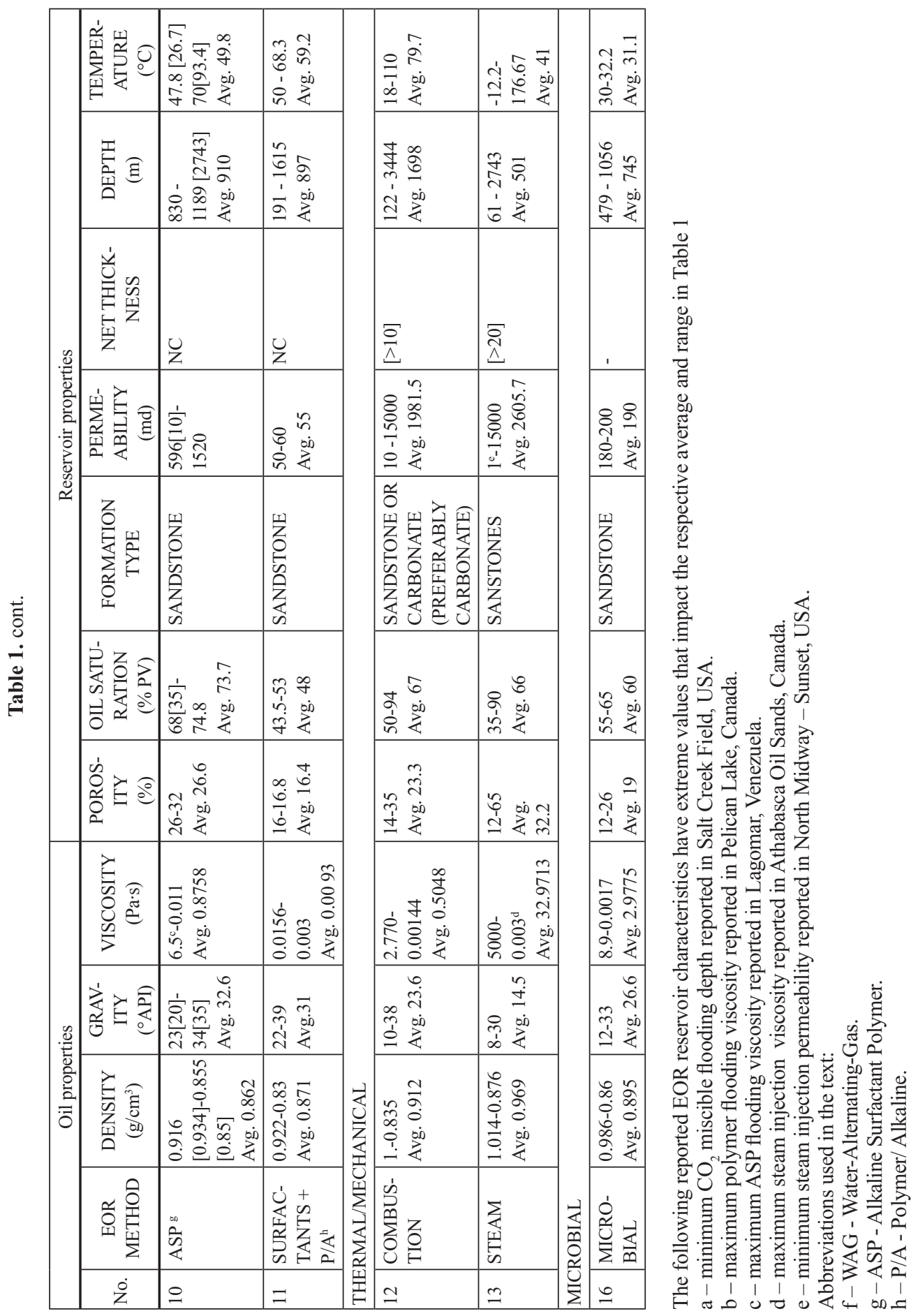


The selection of injected gas mainly depends on its availability in a given location and cost [10]. Injection of $\mathrm{CO}_{2}$ is the most common method in the case of sandstone reservoirs with medium and light oil. The $\mathrm{CO}_{2}$-based methods EOR show a great recovery potential and are broadly documented in literature.

\section{THE EOR METHOD OFFSHORE}

The EOR methods in offshore environment depend not only on the lithology of reservoir but also surface apparatuses, environmental conditions and the like. Therefore implementing EOR methods in offshore environment is a much more complex process than in onshore applications. Space limitations and weight of apparatuses (with the resulting higher cost of operation) have to be accounted for when offshore environment is considered. Offshore drilling is frequently connected with a considerable distance between the wells and smaller information range about the reservoir geology, particularly the continuity between wells.

Prior to selecting the enhancement method which would best fit the environmental conditions one should consider surface and subsurface limitations as well as the availability and cost of the injected agent. The implementation of EOR projects in offshore conditions is associated with considerable technical and economic risk. Therefore, prior to applying a specific method, all limitations and risks should be thoroughly analyzed at the planning stage. In this way the most advantageous EOR method can be selected for given conditions [3]. Recognition of reservoir geology allows for proper modeling of the extraction process. Modeling based on productivity only may turn out insufficient.

There are numerous instances of gas injection application in offshore conditions (Fig. 1). Among chemical methods the most popular are polymer injection methods. The bed combustion method in offshore environment is limited due to the lack of full control of the combustion front. Steam injection is related to considerable heat losses in the well. Microbiological methods have to be preceded by numerous tests before they are applied at a larger scale [4].

a)

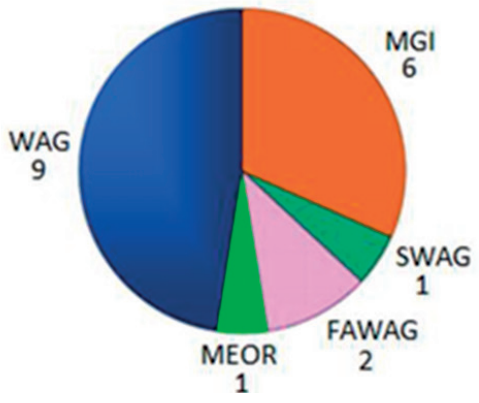

Fig. 1. a) Examples of EOR projects realized in the North Sea; b) possible applications of EOR methods in offshore conditions in Malaysia; Water-Alternating-Gas (WAG); Miscible Gas Injection (MGI); Simultaneous Water Alternative Gas (SWAG), Foam Assisted WAG (FAWAG); Microbial Enhanced Oil Recovery (MEOR) [Alvarado V, 2010) 
The use of EOR method in offshore conditions is more costly as compared with their onshore counterparts. This is caused by logistic, operational and environmental differences. Sometimes a given method may be optimal in view of the assumed extraction mechanisms but turns out nonprofitable economically [5].

\section{THE EOR METHODS USED IN OFFSHORE CONDITIONS IN SANDSTONE RESERVOIRS WITH LIGHT OIL}

The use of a specific enhancement method depends not only on the reservoir characteristic or environmental conditions, but also properties of formation fluid. Specific weight of oil (light, medium and heavy oil) is especially important. The EOR methods used in sandstone reservoirs containing light oil are discussed in the successive paragraphs in greater detail. The processes were selected in view of the offshore applications.

\section{5. $\mathrm{CO}_{2}$ INJECTION PROJECTS}

Depending on the oil composition and reservoir conditions the $\mathrm{CO}_{2}$-EOR projects may be based on mixing of carbon dioxide with oil or may rely on immiscible oil displacement. Majority of EOR projects making use of carbon dioxide injection apply the miscible oil displacement. This is connected with the fact that the oil coefficient obtained with this method is higher. Having assumed the miscibility of carbon dioxide and oil we aim at increasing the volume of oil and lowering its density and viscosity to produce better flow conditions and higher depletion degree. Besides capillary forces, which are responsible for capturing oil in the rock mass are decreased. The production increase realized with the $\mathrm{CO}_{2}$-EOR method can be of 10 to $15 \%$ [17].

Miscible oil displacement takes place when has density resembles that of oil, i.e. Minimum Miscibility Pressure (MMP). Changes in oil composition taking lace as a result of initial transport of volatile hydrocarbon elements to the injected gas enable oil to mix with carbon dioxide in the 'miscibility zone' (Fig. 2). The miscibility can be obtained if proper pressure and temperature exist in the reservoir. Carbon dioxide should be injected at higher pressure than MMP [8].

The pressure needed for injecting $\mathrm{CO}_{2}$ should be lower than for other gases. The feasibility of $\mathrm{CO}_{2}$ miscible oil displacement is also determined on the basis of density and saturation of rocks with oil. Considering saturation of rocks with oil, it should be equal to about 20 to $30 \%$. The miscibility of lighter oils with gas is higher than of heavy oils, therefore they are more easily displaced from the reservoir. The conditions of $\mathrm{CO}_{2}$ mixing with oil are fulfilled if [10]:

- density $<0.825 \mathrm{~g} / \mathrm{cm} 3$, depth $>762 \mathrm{~m}$;

- $0.825<$ density $<0.865$, depth $>853 \mathrm{~m}$;

- $0.865<$ density $<0.887$, depth $>1006 \mathrm{~m}$. 


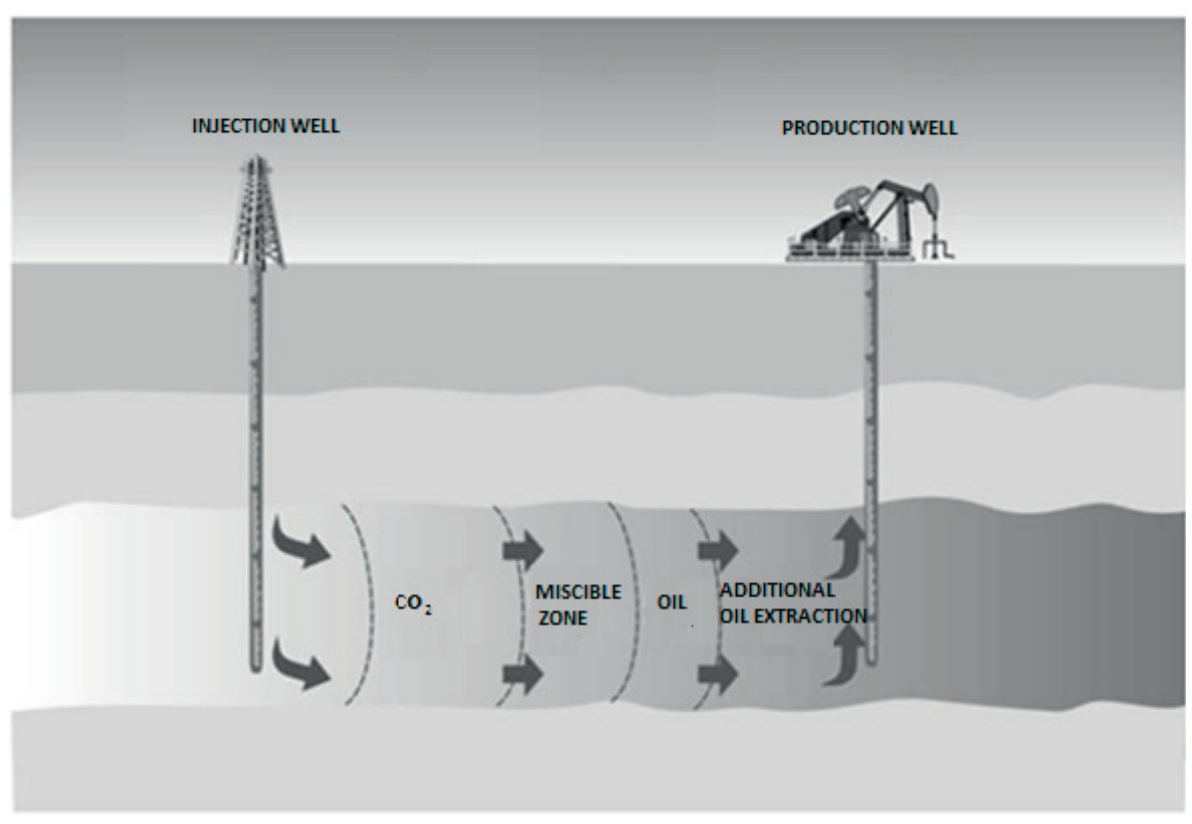

Fig. 2. $\mathrm{CO}_{2}$ miscible oil displacement (Rychlicki S., 2011)

Most of injected gas is either captured in the rock pores or dissolved in formation fluids. Part of it is mixed with oil and transported to the surface where is separated from carbon dioxide, which in turn, can be re-injected to the reservoir. The $\mathrm{CO}_{2}$ injection is connected with the presence of viscous fingering - a result of instability of the displacement front. [16]. This leads to the capturing of oil in the deposit.

If oil pressure is too low and oil density is too high, the immiscible oil displacement method has to be applied (Fig. 3). In this process the reservoir pressure is maintained. The oil becomes more mobile and less dense as $\mathrm{CO}_{2}$ partly dilutes in oil [17].

Carbon dioxide can be injected through hydration wells which is very advantageous both technologically and economically. The $\mathrm{CO}_{2}$ injection should be applied in considerably thick reservoirs. For providing optimum efficiency of the process, the injected carbon dioxide should be $30 \%$ or more of pore volume occupied by hydrocarbons [10].

Additional production with the use of $\mathrm{CO}_{2}$ oil miscible method can be obtained after 1 to 5 years from the day of project implementation. For the immiscible variant the period will be much longer [17].

Carbon dioxide use in the process is recuperated from natural or anthropogenic sources. Presently fossil fuels constitute over $85 \%$ of world's energy consumption which is associated with considerable amount of carbon dioxide emitted to the atmosphere. Seizing flue gases from power stations and utilization of the $\mathrm{CO}_{2}$ component in EOR processes leads to the lowering of carbon dioxide air emissions and the resulting fees. The Carbon Capture and Storage (CCS) technologies and $\mathrm{CO}_{2}$-EOR methods allow for reducing $\mathrm{CO}_{2}$ emissions to the 
atmosphere with simultaneously increased oil production. By combining both processes the cost of $\mathrm{CO}_{2}$ sequestration can be limited. This is connected with, e.g. the use of the already existing infrastructure and knowledge of the process itself. The $\mathrm{CO}_{2}$ sequestration with the use of the $\mathrm{CO}_{2}$-EOR method should be preceded by detailed analysis of geological, geothermal and hydrodynamic conditions. Completely or partly depleted oil and gas deposits are well recognized and constitute perfect storage places for carbon dioxide [16].

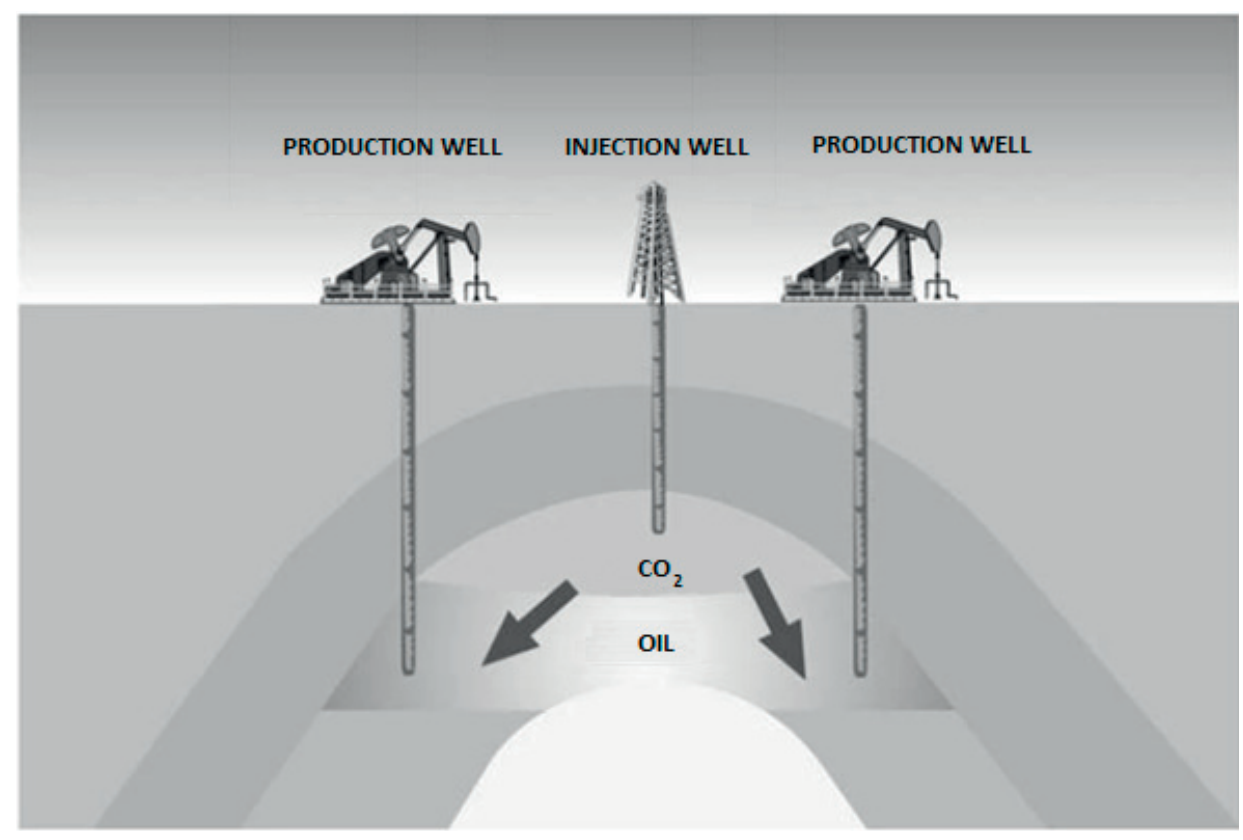

Fig. 3. $\mathrm{CO}_{2}$ immiscible oil displacement (Rychlicki S., 2011)

The limited efficiency of the $\mathrm{CO}_{2}$-EOR process in its miscible and immiscible variant is connected with gravity segregation, presence of viscous fingering and gas displacement to higher-permeability zones [15]. By introducing foam to the $\mathrm{CO}_{2}$-EOR process we decrease the mobility of carbon dioxide thus the above effects.

As far as the mode of $\mathrm{CO}_{2}$ injection is concerned, we have Gravity Stabilized Gas Injection (GSGI) method and Water-Alternating-Gas (WAG) method [17]. In the first method $\mathrm{CO}_{2}$ is injected o the rock mass in its highest zone, as a result of which oil moves down and to the edges of the deposit towards the production well. $\mathrm{The}^{\mathrm{CO}_{2}}$-WAG process lies in alternating injection of carbon dioxide and water. The injected $\mathrm{CO}_{2}$ improves oil mobility, and water facilitates its displacement towards the production well.

The Huff ' $n$ ' Puff method is an alternative solution [16]. Carbon dioxide is injected to the reservoir for a couple of days/weeks after which the process is stopped for a couple of days/ weeks. Then production of oil and carbon dioxide takes place through the well previously used for gas injection. Originally the Huff 'n' Puff process was used for heavy oils, but seems 
very promising for light oils as well. The increase of production grows with the amount of injected $\mathrm{CO}_{2}$, is independent of the minimum miscible pressure. Additional water flooding increases the efficiency of production. A higher production was also observed in the second cycle of $\mathrm{CO}_{2}$ injection; the third cycle turned out to be inefficient.

\section{6. $\quad \mathrm{N}_{2}$ INJECTION METHOD}

Nitrogen can be used for maintaining reservoir pressure in EOR methods making use of gas and oil mixing. The $\mathrm{N}_{2}$ injection method is cheap, commonly available and environmentally advantageous due to the most neutral character of the injected gas. This method is mostly used in deep reservoirs with light oil as the MMP for $\mathrm{N}_{2}$ is highest in comparison to other gases [14].

Despite the fact that injected nitrogen is cheaper than carbon dioxide one should also consider limitations resulting from the offshore conditions in which it will be used, especially the delivery of nitrogen to the wellhead (parameters and pressure as in specifications). These limitations can be eliminated but this operation involves considerable costs. There are a few offshore fields, platform designs and plans of their use which successfully accounted for the problem of providing large amounts of nitrogen to the offshore applications [9].

\section{HYDROCARBON GAS INJECTION METHOD}

In the course of hydrocarbon gas injection in immiscible conditions, the enhanced production is realized with the use of gravity drainage. The injected gas is used for maintaining reservoir pressure and stabilize displacement to increase the reservoir depletion degree. In miscibility conditions, two effects depending on the oil composition and parameters of injected (poor/enriched) gas can be observed, i.e. evaporation and condensation. The hydrocarbon gas miscible projects can be used not only for enhancing production but also for creating underground gas storages. Higher production is observed much more frequently when gas is injected to the upper part of the reservoir rather than to the lower part.

Hydrocarbon gas injection is recommended for thin formations. The presence of highly permeable zones in a reservoir considerably reduces advantages resulting from the applied process. Prior to implementing the project the economic feasibility analysis should be made. The injection of hydrocarbon gas may turn out to be less profitable than just selling it [10].

\section{FLUE GASES INJECTION METHOD}

The flue gas is one of the cheapest gases used with EOR methods. The most favorable effects were obtained for low-viscosity oil and deep reservoirs. Flue gases injection results in increased volume of being a consequence of $\mathrm{CO}_{2}$ dissolving and considerably lower viscosity. In the process of flue gases injection the miscible displacement takes place as a consequence 
of evaporation of light components of oil, provided the pressure is sufficiently high. The injected gas may be also used as displacing gas if a big part of porous space has been filled with it. The flue gases contain about 85 to $88 \%$ of $\mathrm{N}_{2}$ [11], therefore the criteria assumed when selecting the most appropriate $\mathrm{N}_{2}$ EOR method are similar to those for flue gases.

Among the shortcomings of this method are liability to viscous fingering formation and corrosion. Prior to applying this method in offshore environment, detailed analysis of flue gas deliveries should be made. The equipment needed for gas capturing, cleaning and compressing should be accounted for. The best results were obtained for low viscosity $(<0.0004 \mathrm{~Pa} \cdot \mathrm{s})$ light oil $\left(>35^{\circ} \mathrm{API}\right)$ and deep reservoirs (>1800 meters). [11].

\section{WATER-ALTERNATING-GAS (WAG) METHOD}

This method lies in alternating injection of gas $\left(\mathrm{CO}_{2}\right.$, hydrocarbon gas, $\left.\mathrm{N}_{2}\right)$ and water to stabilize the displacement front. This mechanism is responsible for displacement of oil from inaccessible parts of the reservoir only with water. According to the mechanism of gravity forces the flooded water displaces oil from the lower parts of reservoir and gas from the upper zones. Gases injected to a reservoir lower the oil viscosity, influence the character of solids wettability and affect the relative permeability of oil. Additionally, the gases are responsible for increased gassing of oil and lower mobility of water. The application of $\mathrm{CO}_{2}$ allows for obtaining higher productions as compared to the use of $\mathrm{N}_{2}$ or hydrocarbon gas. When water is used in the WAG method, the reservoir is exploited more evenly and more efficiently, besides the $\mathrm{CO}_{2}$ use is reduced. The process involving immiscible oil production increases the yield by about $5 \%$, whereas the miscible variant increases the production by $10 \%$ or even $20 \%$ [7].

Depending on the quantity of injected gas and injection rates the following WAG schemes can be distinguished. The $\mathrm{CO}_{2}$-WAG models are presented in Fig. 4. The mobility limitations of both phases resulting from the assumed injection scheme allow for resucing the risk of the viscous fingering formation [17].

Considerable distances between wells typical of offshore situations disadvantageously influence the course of WAG procedure. However, their reduction has a significantly negative influence on the cost of the enterprise. The WAG technology is very sensitive to the reservoir heterogeneity which limits its applicability. Most of successful projects are reduced to low-permeability and limited-thickness reservoirs. This method is associated with the risk of gas stops in the zone around the injection wells and corrosion. Flooded reservoirs get cooler around the well and gas injection in the WAG process may result in the formation of hydrates [7].

In the course of WAG applications it is important to select proper quantities of gas with respect to the amounts of injected water. Gas constitutes a great part of the total cost in this method. The WAG process is quite expensive except the situations when excessive gas is available.

Foam can be used in the WAG process, i.e. Foam Assisted WAG (FAWAG). The foam is used for controlling gas mobility and sealing selected zones of the rock mass. In this way 
bigger amounts of gas can be injected to less permeable strata and displace the residing oil. There are also examples of technologies employing Simultaneous Water Alternative Gas (SWAG) method. Few field applications making use of this method can be indicated, however. Additionally, the WAG method seems to be more advantageous and easier to implement than SWAG. Simultaneous injection of water and gas should be monitored due to the instability of the process being a consequence of segregation of the injected phases [7].

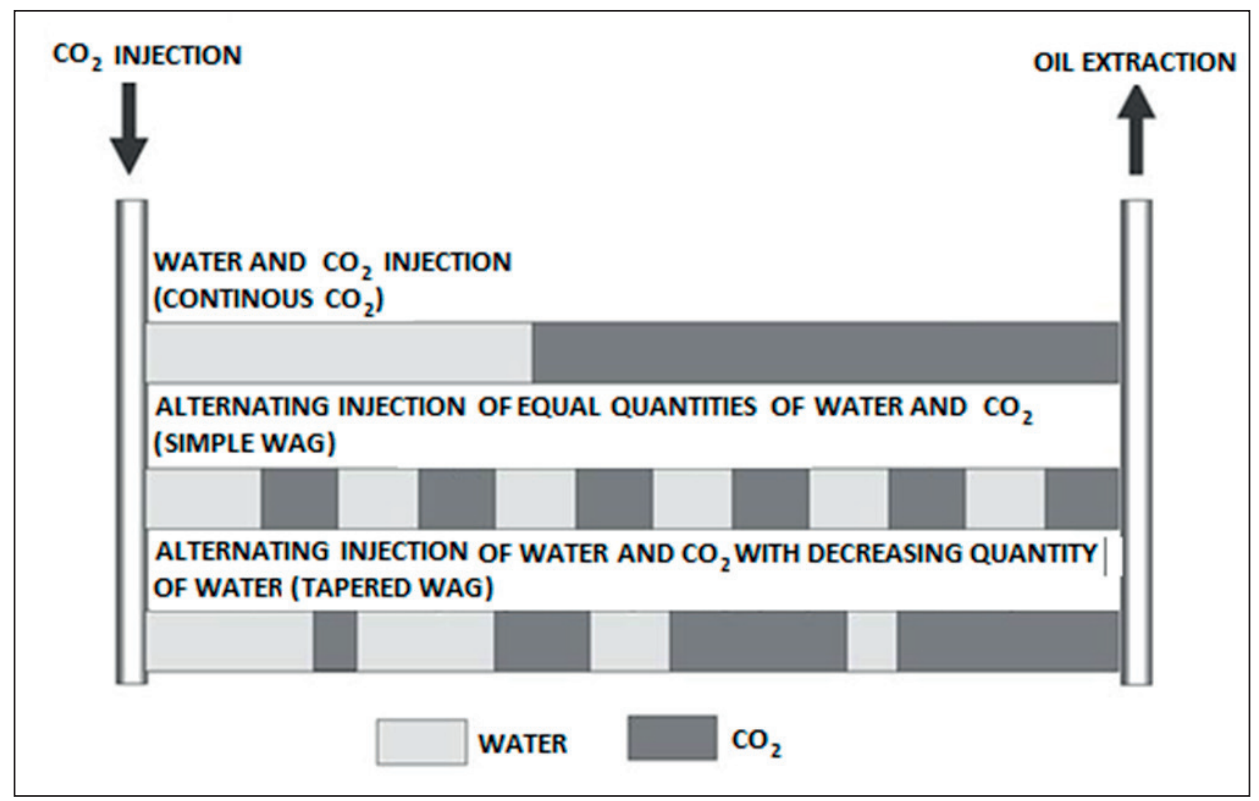

Fig. 4. Schematic of $\mathrm{CO}_{2}$-EOR method (WAG) [Rychlicki S., 2011]

\section{FOAMASSISTED GAS INJECTION}

Foam is a mixture in which fluid together with a surfactant form a continuous phase which wets the rock; the gas bubbles are separated by fluid layers (dispersed phase) [15].

In the case of gas injection EOR methods there appears a problem of considerably higher mobility of injected agent as compared to oil. This results in premature appearance of injected gas in the production well and also lower depletion coefficient. The use of foam allows for lowering the mobility of injected gas in porous media. The efficiency of the process depends on the gas injection stability in the presence of oil [7]. The use of foam during gas injection is aimed at improving the efficiency of oil displacement and lowering of the gas/oil coefficient. The injected gas can be also directed with the use of the applied foam [1].

The unfavorable ratio of mobility and density contrast between the injected agent and oil lowers the efficiency of displacement. The injected gas may be also captured in the formation as a result of adsorption. Foam injection limits the occurrence of this type of effects. 
Three types of foam formation can be distinguished [19]:

- injection of preliminarily prepared foam - foam prepared outside of the porous medium, can be generated on the surface with the use of a foam generator or flow in the well or just before entering the formation - Perforations Generated Foam (PGF).

- Co-injection - is generated in situ, close to the injector, surfactant and gas are injected simultaneously.

- Surfactant Alternating Gas (SAG) - alternating injection of a surfactant and gas.

The preliminarily prepared foams have higher resistance coefficients than their counterparts which may lead to the total blocking of the porous space. When selecting between various types of foam production (SAG, co-injection or preliminary preparation of foam) the following factors should be accounted for: reservoir pressure, permeability and expected time of surfactant injection. The preliminarily prepared foam can be efficiently used during processes performed in production wells, whereas co-injection and SAG can be used for enhancing the efficiency of displacement.

Depending on the application, the following foams can be distinguished: Mobility Control Foam (MFC), Blocking/Diverting Foam (BDF) and foams regulating the gas/oil coefficient [19].

The foam injection mechanism has not been recognized to an extent warrantying a successful application of the method. The applied foams do not give certainty as to their behavior as they propagate over long distances in a porous medium. Additionally, the transport, supplies and storing of chemicals used in the process in offshore conditions is much more complicated than onshore. It should be remembered that foam in high temperatures may undergo degrading. The foam type and the assumed injection model should be adjusted to the particular application. Foam injection should not be used individually, but only for improving the EOR process [19].

\section{AIR INJECTION METHOD}

The High Pressure Air Injection (HPAI) method lies in high pressure air injection $(78 \%$ $\mathrm{N}_{2}$ and $21 \% \mathrm{O}_{2}$ ). Oxygen reacts with hydrocarbons in the reservoir. There are two possible ways of oxidation: combustion and attachment of oxygen. The attachment of oxygen particles to the molecular structure of liquid hydrocarbon results in the formation of various oxides (hydrogen peroxide, aldehyde, ketones and acids), which in the course of further reactions form heavier, less desired oil fractions. The removal of oxygen from the gaseous phase causes lower pore pressure. These reactions are predominantly observed under $150^{\circ} \mathrm{C}$ for light oils and are connected with limited permeability or insufficient amount of injected air. In the case of light oils the combustion usually takes place at temperatures $150^{\circ} \mathrm{C}$ to $300^{\circ} \mathrm{C}$. Flue gases $\left(\mathrm{N}_{2}(85\right.$ to $90 \%), \mathrm{CO}_{2}(10$ to $15 \%), \mathrm{CO}(1$ to $\left.2 \%)\right)$ and steam are produced in the 'combustion zone' making oil move, swell and heat up. Lower viscosity oil can be moved more easily [11]. 
If the depth and temperature of light oil reservoirs are sufficient to initiate spontaneous ignition and combustion of hydrocarbons in situ, the air injection process can be successfully applied [13].

The combustion in situ, used after reservoirs containing light oil have been flooded, is of great potential. This process may increase the production in a relatively short time. The ongoing air injection projects are realized in thin carbonate layers of low permeability, therefore employing this option for sandstones is a high risk project [13]. The nearly unlimited access to the active element (air) is particularly important in the case of offshore applications. This process has been successfully applied both in laboratory and in field conditions. The HPAI method may increase the production by 5 to $15 \%$ of Original Oil In Place (OOIP).

\section{POLYMER INJECTION METHOD}

Among chemical EOR methods polymer injection (Fig. 5) is most frequently applied offshore. Polymers are salinity-sensitive therefore their higher concentration have to be used in the sea water-based processes, thus increasing the cost of the operation. Accordingly, the cost of desalination versus cost of higher amounts of polymers should be analyzed. Moreover, analogous to surfactants, polymers may behave unstable in the reservoir temperature conditions. After flooding the residual oil does not form a continuous phase; instead it is dispersed in the rock pores. The chemical methods are aimed at reducing Interfacial Tension (IT) between oil and water, allowing residual oil to migrate. The main purpose of polymer injection is the mobility control. Polymers should penetrate the low-permeability zones as deeply as possible to displace the captured oil. The use of polymers is costly therefore the number of implemented projects is relatively small.

Two types of polymers are usually used in the chemical EOR methods, i.e. HPAM (Hydrolyzed Poly-Acrylamide) and xanthan gum (polysaccharide biopolymer). Acryloamides are not fit for highly saline waters. Lower performance of HPAM in the case of saline water is most important when viscous oil is involved. The HPAM is cheaper than polysaccharide biopolymers. Under the influence of shearing stresses the polymeric chains are destroyed (mechanically degraded). The HPAM are sensitive to temperature and electrolytes. In higher temperatures in the presence of bivalent ions of, e.g. calcium or magnesium the cloud point may be observed. The polymer precipitates from the solution in the form of a wax-like solid polymeric substance. Xanthan gum is appropriate for highly saline waters and insensitive to mechanical degradation. However, polysaccharide biopolymers may block the pore spaces and make the flow impossible. Besides they are very expensive and liable to bacterial degradation [6].

The polymer concentrations in the injected water usually equal to about 500 to 2500 ppm. The polymers are added to increase the viscosity of water phase and so lower the oil/ gas mobility coefficient. In this way the flow can be stabilized (Fig. 6) improving vertical and surface displacement efficiency [6]. In the case of highly nonhomogeneous reservoirs (fracturing, considerable permeability of parts of the reservoir) the polymers will enable water 
to penetrate low permeability parts of the reservoir. Additionally, the oil recovery process is realized with lower quantities of water.

A considerable distance from the land limits the availability of polymers and necessitates their storing, which makes the method more expensive. When polymers are to be used in offshore conditions it is necessary to account for the considerable distance between the wells and distribution of polymers at considerable distances. Besides, seawater sometimes has to be desalinated and degassed.

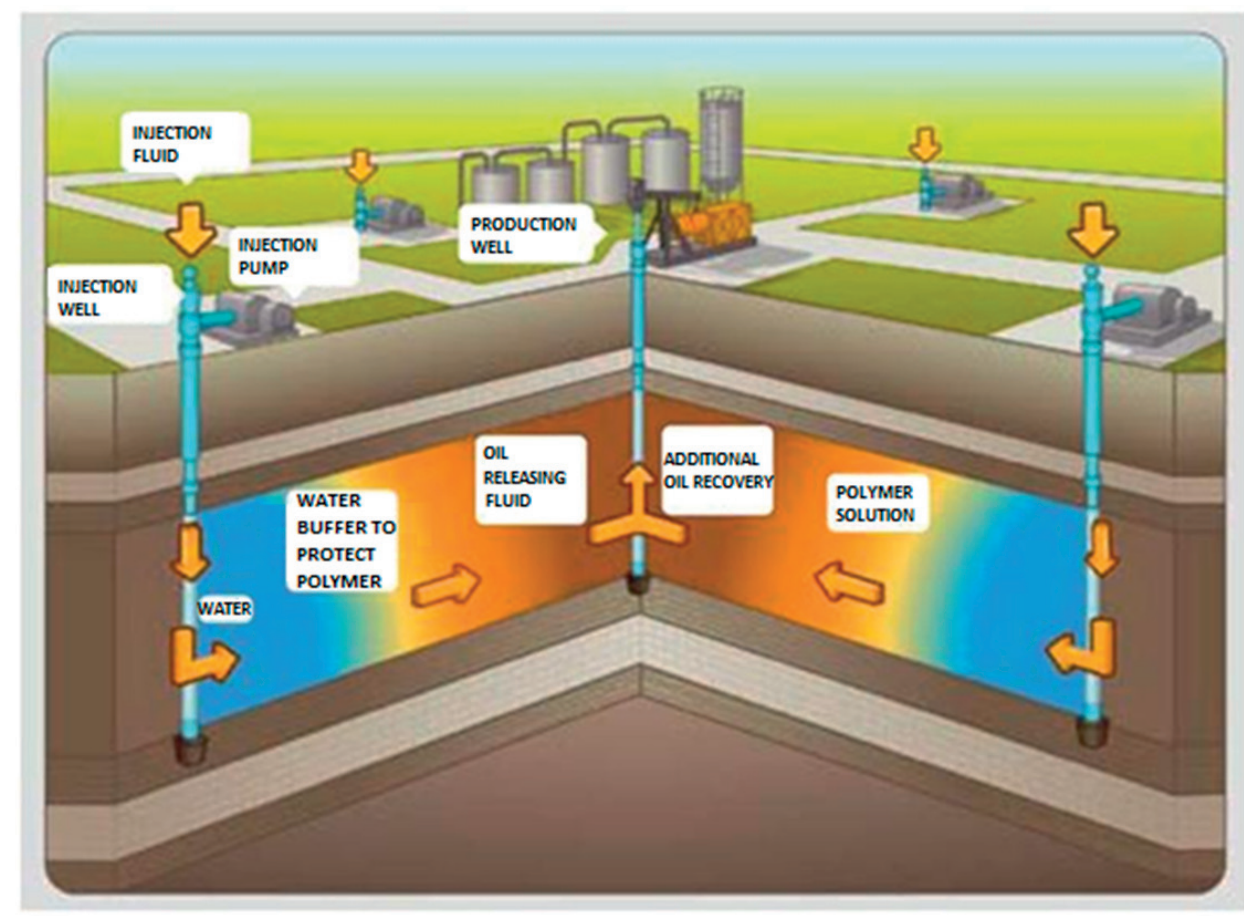

Fig. 5. Schematic of EOR polymers injection (Kosowski P., 2010).

Polymers may be used both as solids (powder) or liquid (emulsion). The HPAM powder is a cheaper solution and requires less storing space. Prior to injecting, the powder undergoes complex processing. Handling of emulsion is much easier. Powder has to be maintained dry during the transport and storing. Considerable distances between wells cause that polymers are exposed to mechanical degradation, therefore in offshore conditions it is necessary to establish an additional amount of polymers to be injected to reduce this effect. It is usually extra 20 to $30 \mathrm{wt} . \%$ which are added to compensate for the shearing losses and obtain the required viscosity in the reservoir [6].

The produced water frequently contains certain amounts of chemicals and oil. The removal of excessive components is not easy in offshore conditions, therefore this water is frequently re-injected. 

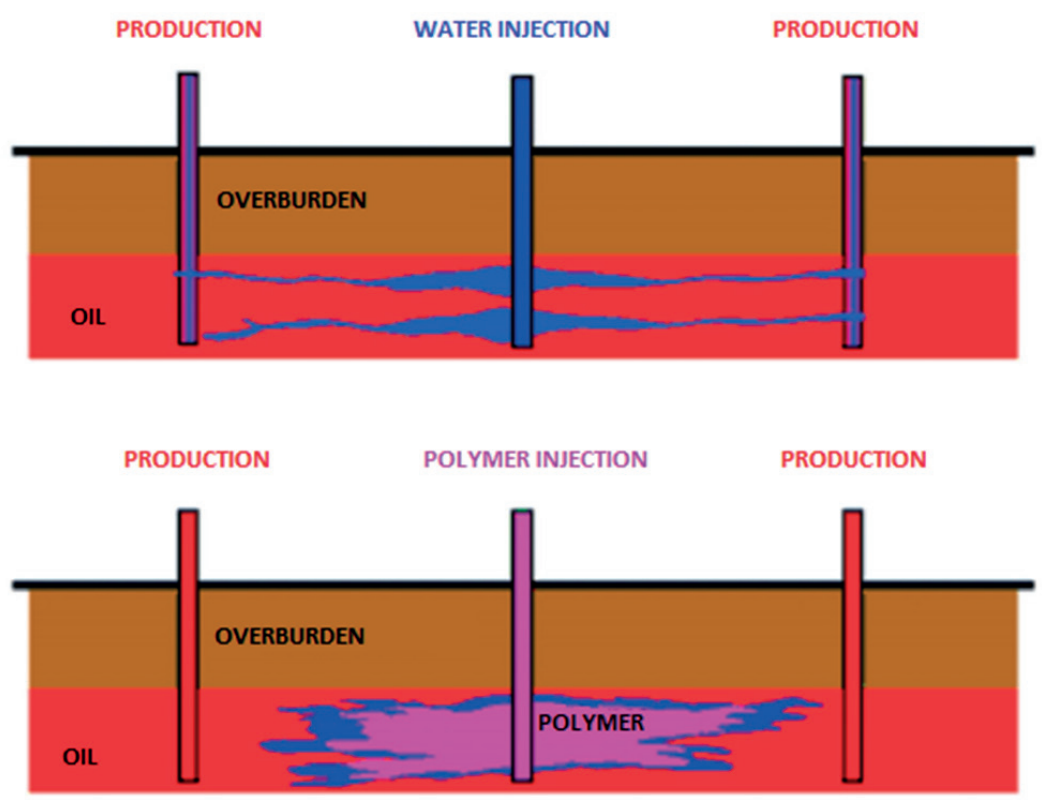

Fig. 6. Effects of vertical flow stabilization provided by polymers [Ayirala S., 2011]

\section{ALKALINE SURFACTANT POLYMER (ASP)}

The ASP technology makes use of alkali, surfactants and polymers with the objective to increase the displacing abilities and reduce the oil/water IFT [6]. Surfactants used for decreasing the interfacial tension and mobilize residual oil. Surfactant particles have a polar structure. The hydrocarbon radical is most frequently the hydrophobic element, whereas neutralized carboxyl and sulfonic groups connected by hydrocarbon chain make the hydrophilic element. Owing to their structure the substances may be attached equally to water and to oil particles [16]. The use of surfactants is greatly conditioned by the permeability of reservoir rocks. Their applicability in offshore situations may be limited by their degradation in high temperatures, adsorption on minerals, influence of salt, transport and storing of chemicals. In the ASP the expensive surfactants can be reduced and substituted with cheaper alkali, making the process economically viable. Alkali react with organic acids present in oil forming natural surfactants. The presence of alkali increases the surface charge on the rock surface, thus reducing surfactant losses caused by adsorption [18]. Alkali are sensitive to metal ions in hard water, e.g. sea water. The addition of a polymer in the ASP method increases the displacement efficiency.

The ASP method is predominantly used in sandstone formations. However, attention should be paid to the presence of clays and adsorption of surfactants. Limitations related to 
the use of the ASP method in offshore conditions are mainly connected with high temperature inside the reservoir, salt content, considerable space needed for storing chemicals and high cost. The big distance between wells extends the time when economic profits from the discussed process can be seen. The re-injection of produced water lowers cost of chemicals and has an environmental value. Sometimes the field limitations exclude the use of polymers or alkali with the ASP method. In such a case the method has to be modified accounting for the use of surfactants and polymers or alkali and surfactants (SP or AS). Only few alkali (e.g. sodium metabisulfite) can be used with sea water.

There can be also used the surfactant-polymer (SP) method, though considerable amounts of surfactants have to be involved. Standard polymers are not applicable at temperatures exceeding $80^{\circ} \mathrm{C}$. The alkali-surfactant (AS) method makes use of foam for increasing the mobility of oil. This method is applicable in the case of heavy oil [6].

\section{MICROBIAL ENHANCED OIL RECOVERY (MEOR)}

Microorganisms may be used for cleaning the wells and for enhancing the hydration process. The MEOR method enhances oil movement and reduces reservoir acidity. MEOR depends on the type of microorganisms used, availability of food components, presence of oxygen (aerobes, anaerobes) as well as reservoir and fluid properties. Sea water injection created good temperature conditions for this method. This is the cheapest of all EOR methods. To obtain the required concentration of bacteria in MEOR aerobic processes, a suitable amount of $\mathrm{O}_{2}$ has to be injected to enable their growth. At the stage of planning attention should be paid to the fact that the presence of oxygen may cause corrosion of particular parts of the applied system. Anaerobic processes require considerable amounts of food (sugar), being a considerable constrain. MEOR can be used when the salinity does not exceed $150 \mathrm{~g} / 1$ [7].

\section{CONCLUDING REMARKS}

The objective of EOR methods is to extend the oil recovery time and increase its efficiency at the initial stage of the production process. When selecting a method for specific reservoir conditions attention should be paid to the formation making up the reservoir rocks and properties of formation fluids. The characteristic of the reservoir should cover: porosity of rock, saturation with oil, type of formation, permeability of rocks, depth of deposition, effective thickness and reservoir temperature. Among the parameters characterizing formation fluids are: density of oil, its viscosity and hydrocarbon composition.

The EOR methods applied in offshore environment mainly depend on: geology of reservoir, distribution of wells, surface systems (its size and weight), environmental conditions and availability of the injected agent. The implementation of EOR methods in offshore conditions is much more complex than onshore. The influence of sea water environment should be accounted for both at the planning stage, designing stage and finally when managing the EOR process. 
The tertiary oil production methods were analyzed. More detailed discussion was devoted to the EOR methods used in sandstone formations with light oil and which are applicable in offshore environment field. The remaining processes, meeting only some of the conditions, were only mentioned. The list of applicability criteria of particular methods with reservoir parameters and oil properties can be useful when selecting the most efficient methods. The applicability criteria of particular methods are presented in table 1.

Thermal methods refer to most of the high-density and high-viscosity oil deposits. In the case of reservoirs containing light oil the steam injection does not play any important role. Now the high pressure air injection (HPAI) methods grow in significance; however, this technology has not been used for sandstone reservoirs yet. Among chemical methods, most commonly used in offshore situations, is the polymer-based method. The ASP method is also more and more popular. The technologies employing gas injection mechanism in oil miscible conditions are most frequently applied in reservoirs containing light oil. The use of a specific gas in EOR methods must be however preceded by an analysis of its availability and economic viability. There are numerous examples illustrating how methods relying on gas injection have been operating in offshore conditions. Microbiological methods have not been developed well enough yet therefore their large-scale applications must be preceded by very careful and thorough analyses.

\section{REFERENCES}

[1] Aarra M. G., Martinsen H. A., Skauge A., 2002. FAWAG: A Breakthrough for EOR in the North Sea. SPE Annual Technical Conference and Exhibition, 29 September-2 October, San Antonio, Texas. SPE 77695.

[2] Aladasani A., Bai B., 2010. Recent Developments and Updated Screening Criteria of Enhanced Oil Recovery Techniques. International Oil and Gas Conference and Exhibition in China, 8-10 June, Beijing, China. SPE 130726.

[3] Alvarado V., Izadi M., Lantz M., Manrique E., Ravikiran R., Romero J., Thomas C., 2010. EOR: Current Status and Opportunities. SPE Improved Oil Recovery Symposium, 24-28 April, Tulsa, Oklahoma, USA. SPE 130113.

[4] Alvarado V., Manrique E., 2010. Enhanced oil recovery. Field planning and development strategies. Elsevier Inc. (Gulf Professional Publishing), ISBN 978-1- 617-855-6.

[5] Avasthi S. M., Bondor P.L., Hite J.R., 2005. Planning EOR Projects in Offshore Oil Fields. SPE Latin American and Caribbean Petroleum Engineering Conference, 20-23 June, Rio de Janeiro, Brazil. SPE 94637.

[6] Ayirala S., Chin R., Raney K., Verbeek P., 2011. Surface and Subsurface Requirements for Successful Implementation of Offshore Chemical Enhanced Oil Recovery. Offshore Technology Conference, 2-5 May, Houston, Texas, USA. OTC 21188.

[7] Awan A. R., Kleppe J., Teigland R., 2006. EOR Survey in the North Sea. SPE/DOE Symposium on Improved Oil Recovery, 22-26 April, Tulsa, Oklahoma, USA. SPE 99546. 
[8] Bath P. G. H., van der Burgh J., Ypma J. G. J., 1983. Enhanced Oil Recovery in the North Sea. 11th World Petroleum Congress, 28 August -2 September, London, UK. WPC 20219.

[9] Bywater, D.R., Clancy, J.P., Cheng, L.H.K., 1985. Analysis of Nitrogen-Injection Projects to Develop Screening Guides and Offshore Design Criteria. Journal of Petroleum Technology 37(6), 1097-1104.

[10] Danquigny J., Guarrino A., Hunedi S., Maubeuge F., Morel D., 2005. Applicability of Enhanced Oil Recovery techniques on mature fields - Interest of gas injection. SPE Middle East Oil and Gas Show and Conference, Mar 12 - 15, Kingdom of Bahrain. SPE 93368.

[11] Hawboldt K., Iliyas A., Johansen T., Khan F., Thomas B., 2010. Towards Sustainable and Environmentally Friendly Enhanced Oil Recovery in Offshore Newfoundland, Canada. Offshore Technology Conference, 3-6 May, Houston, Texas, USA. OTC 20385.

[12] Kosowski P., Rychlicki S., Stopa J., Wojnarowski P., 2010. Metody zwiększenia efektywności wydobycia ropy naftowej. Przemysł Naftowy w Polsce. AKNET, Kraków , s. 22-36.

[13] Koundin A., Surguchev L. M., Yannimaras D., 1999. Air Injection - Cost Effective IOR Method to Improve Oil Recovery from Depleted and Waterflooded Fields. SPE Asia Pacific Improved Oil Recovery Conference, 25-26 October, Kuala Lumpur, Malaysia. SPE 57296.

[14] Martin F. D., Seright, R. S. Taber J. J., 1997. EOR Screening Criteria Revisited Part 1: Introduction to Screening Criteria and Enhanced Recovery Field Projects. SPE Reservoir Engineering, 12(3), 189-198.

[15] Masoudi R, Talebian S. H., Tan I. M., Zitha P. L. J., 2013. Foam assisted $\mathrm{CO}_{2}-$ EOR; Concepts, Challenges and Applications. 2013 SPE Enhanced Oil Recovery Conference, Jul 02 - 04, Kuala Lumpur, Malaysia. SPE 165280.

[16] Rychlicki S.(red.), 2010.Możliwości zwiększenia efektywności wydobycia ropy naftowej ze złóż karpackich. Wydawnictwa AGH, Kraków.

[17] Rychlicki S., Stopa J., Ulisz-Misiak B., Zawisza 1., 2011. Kryteria typowania złóż do zastosowania zaawansowanej metody wydobycia ropy naftowej poprzez zatłaczanie $\mathrm{CO}_{2}$. Gospodarka Surowcami Mineralnymi 27(3), 125-139.

[18] Skauge A., Skauge T., Spildo K., 2010. Propagation of Colloidal Dispersion Gels (CDG) in Laboratory Corefloods. SPE Improved Oil Recovery Symposium, 24-28 April, Tulsa, Oklahoma, USA. SPE-129927-MS

[19] Singhal A. K., Turta A.T., 2002. Field Foam Applications in Enhanced Oil Recovery Projects: Screening and Design Aspects. Journal of Canadian Petroleum Technology, 41(10). 